\title{
PRELIMINARY CLINICAL STUDY ON MS TREATMENT WITH HYPERBARIC OXYGENATION
}

\author{
Kazimierz Ulewicz, Janusz Masłowski, Przemysław Michniewski, Brunon Kierznikowicz, Romuald Olszański
}

From the Department of Human Epidemiology and Ecology of the Institute of Clinical Medicine, Medical Academy of Cracow in Rzeszów, Maritime and Tropical Medicine Institute of Gdynia, Maritime Medicine Institute of the Warsaw Medical Academy in Gdynia, Poland

\section{ABSTRACT}

The authors conducted the preliminary clinical investigation on 16 multiple sclerosis (Sclerosis multiplex) patients of median disease duration 9.33 years and symptoms evaluated on Kurtzke's scale. The patients underwent between 25 and 30 hyperbaric oxygen exposures at a pressure of 2 ata in intervals spread over a few days. The patients were qualified and classified to the treatment symptomatologically according to Fisher but the obtained results were evaluated according to the standardised Disability Status Scale by Kurtzke. During the investigations the authors carried out additional quantitative immunoglobulin and complement activity determination, lymphocyte $\mathrm{T}$ and $\mathrm{B}$ determinations as well as the usually applied clinical and laboratory investigations. Evident clinical improvement was observed in 14 patients, but in the case of one patient a deterioration was observed after 15 hyperbaric expositions (resulting in the hyperbaric oxygen treatment being stopped), whilst in another case no curative effect could be observed. By utilising the $50 \%$ haemolysis method, within the examined immunological parameters the authors observed an increase of complement fractions and its activity, white lymphocytes $\mathrm{T}$ and $\mathrm{B}$ examined qualitatively did not maintain the characteristic shift. The authors are still discussing the obtained results. Key words: hyperbaric oxygen, sclerosis multiplex, therapy.

\section{ARTICLE INFO}

PolHypRes 2015 Vol. 51 Issue 2 pp. 47-54

ISSN: $1734-7009$ elSSN: $2084-0535$

DOI: $10.1515 / \mathrm{phr}-2015-0010$

Pages: 8 , figures: 5 , tables: 0

page www of the periodical: www.phr.net.pl

Publisher

Polish Hyperbaric Medicine and Technology Society

\section{Original article}

Date of approval for print in PolHyp Res.: 02.06.2014 r.

Originally published in materials of the Conference " Treatment with hyperbaric oxygen therapy" 1988 


\section{INTRODUCTION}

Multiple sclerosis (MS) incidence among European populations within our climate zone reaches 60 cases per $100.000+$ ), and according to Pugliese and Missio (1977) the condition affects mainly young males. Nonetheless, based on the epidemiological studies by Troilles and others (1971) it is possible to assume that more cases are observed in the central and western European countries along the coast of the Atlantic. Its etiology is not known, however recent findings point to viral etiology (possibly the measles virus or a different paramyxo, the so-called Carp factor or other viral factors, including some RNA viruses which implicate an impact on the complementary provirus to DNA virus).

The virus may reside in an organism over a long period of time in a hidden state under the control of reverse transcriptase (Pugliese and Mission - 1977). Of course, other factors also play a role in the etiology of the disease, including genetic, infectious and toxic agents, and others still unrecognised (Gozzano - 1970).

MS is characterised by its chronic character with remissions occurring independently or as an effect of various treatment methods, yet in truth, currently it is only possible to apply symptomatic treatment (Bauer 1978, Rose et al. - 1968). Ultimately, the condition leads to physical disability upon the lapse of several years or decades. At present, there is no existent causal therapy or effective treatment methods. In recent years numerous works have been conducted in relation to the application of hyperbaric oxygenation in treating MS.

Positive results were reported (Kurtzke -1965 , Neubauer - 1978, 1985, James - 1982, 1983, Fisher et al. - 1983, Davis - 1984, Formai et al. - 1980), while at the same time it was emphasised that the described outcomes were not entirely convincing, and taking into account the difficulty in the adjustment of this method, it is not accepted by the majority of researchers (Brown -1980 , Perrins - 1984, Barnes et al. - 1985). Critical works on such studies (Bauer - 1978, Rose et al. - 1968) raise accusations concerned, among other things, with the insufficient number of cases in controlled placebo groups (Fisher et al. - 1983, Perrins - 1984), and frequently also the absence of a control group.

Despite these reservations, following the assumption that the course of MS involves, for instance, the occurrence of demyelinisation, with the immunological system certainly playing an important role, as well as based on previous experimental and clinical studies indicating the immunosuppressive effects of hyperbaric oxygenation (Zannini and Ulewicz - 1986), it was decided to use our material to examine the effect of hyperbaric oxygenation on the course of MS.

An additional element which encouraged the authors to carry out the research that was first commenced as early as 1986 at the Institute of Maritime and Tropical Medicine in Gdynia consisted in obtainment of medical justification for the application of hyperbaric oxygenation in such cases, determining its effect in the periods of aggravation and assessing the curative value of this condition. In the years 1986-1988, altogether 69 patients with diagnosed MS at various stages of the disease were treated at the Clinic of Occupational and Tropical Diseases of the Institute of Maritime and Tropical Medicine of Gdynia. From this group 16 patients were selected for preliminary clinical evaluation.

\section{MATERIAL AND METHOD}

The object of the study and observation were 16 MS patients aged between 18-60 years (average age of 34.86). The patients with diagnosed MS were qualified for hyperbaric oxygenation treatment by the district neurologist, whereas the evaluation, documentation and periodic specialist examinations were conducted by a neurologist from the Hyperbaric Medicine Department of the Institute of Maritime and Tropical Medicine.

The patients were subject to general medical examinations, as well as laryngological and laboratory tests in order to exclude any contraindications for treatment implementation. It should be noted that MS patients with significant impairment to the musculoskeletal system (contractures, significant muscle atrophies or patients who, due to these reasons were long-term bedridden) were not qualified for treatment. Clinical documentation was carried out according to a model from the Mayo Clinic (USA), whereas evaluation of the results was carried out according to Kurtzke's Disability Status Scale (Kurtzke - 1965, 1980). Patients subject to hyperbaric oxygenation were not administered any medicines with effect on the immunological, neurological or muscular system.

During the conducted research, apart from continuous clinical observation and the commonly applied additional laboratory tests, additional determinations were performed for immunoglobulins IgG, IgM, IgA, IgD, complement activity following the $50 \%$ haemolysis method, and determinations of its C3 and C4 fractions, determinations of lymphocytes $\mathrm{T}$ and $\mathrm{B}$ (ARFC, TRFC, EAC tests), leukocytosis, as well as lymphocyte population percentage. Immunoglobulin determination was carried out according to the radial immunodiffusion test (PARTIGEN Behring-Werke), the determination of the complement and its fractions being defined according to the radial immunodiffusion test (MEGA Company), complement activity being identified via the $50 \%$ haemolysis method modified by Tagliaferro, whereas ARFC, TRFC and EAC tests were completed as per Pawelski (1983). All of the above determinations were performed before treatment commencement as well as upon its completion.

Among the 16 patients qualified for hyperbaric oxygenation treatment, 13 were patients with a chronically progressing condition with periods of remissions and exacerbations, often only of progressive character. In 3 patients the condition was of a stationary character with symptoms becoming fixed after an acute initial phase. All of the subjects were able to move independently, whereas in two cases the patients used a cane or crutches.

Initial characterisation of the patients is presented in table 1 . 
Initial characterisation of MS patients subject to hyperbaric oxygenation treatment.

\begin{tabular}{|c|c|}
\hline Number of patients & 16 \\
\hline Men & 8 \\
\hline Women & 8 \\
\hline Average age $\mathrm{x}$ & 34.86 \\
\hline $\mathrm{SD} \pm$ & 5.84 \\
\hline Average time of disease duration $\mathrm{x}$ & 9.33 \\
\hline $\mathrm{SD} \pm$ & 6.64 \\
\hline Average Disability Status Scale before x & 3.4 per 2.1 \\
\hline and after $\mathrm{SD} \pm$ treatment & 1.1 per 1.3 \\
\hline Chronically progressive disease & 13 \\
\hline Stationary disease & 3 \\
\hline
\end{tabular}

The treatment of 16 MS patients qualified to undergo hyperbaric oxygenation was carried out in a hyperbaric chamber, with patients remaining in a lying down position, breathing with pure oxygen at the pressure of 2 ata 02 through a mask, with exhalation performed outside the chamber, with air being compressed in the chamber at the same pressure value.

Hyperbaric exposure lasted 60 minutes. In the course of the treatment a physician specialised in underwater medicine was present in the hyperbaric chamber and two technicians operated the chamber from outside. Generally, the treatment consisted of 15-30 exposures carried out 5 times a week.

\section{RESULTS}

Among the 16 MS patients subject to hyperbaric oxygenation, 13 indicated improvement, one showed no changes within the nervous system following the treatment, whereas one indicated deterioration as a result of which the treatment was discontinued after 15 hyperbaric exposures. Table 2. presents results of hyperbaric oxygenation after 25-30 exposures.

Hyperbaric oxygenation treatment results in MS patients after 25-30 exposures

\begin{tabular}{ll} 
Syndromes-symptoms acc. to Fisher et al. (1983). Improvement per all cases with the specified symptoms-syndromes. \\
\hline Mobility & $15 / 17$ \\
\hline Imbalance & $9 / 10$ \\
\hline Fatigability & $10 / 13$ \\
\hline Intention tremor remission & $4 / 9$ \\
\hline Romberg symptom remission & $3 / 5$ \\
\hline Nystagmus remission & $2 / 3$ \\
\hline Control of urinary bladder sphincters & $4 / 7$ \\
\hline Pyramidal symptoms & $4 / 17$ \\
\hline Sensory system symptoms & $3 / 8$ \\
\hline Symptoms from the organ of vision & $0 / 2$ \\
\hline
\end{tabular}

The above table illustrates that the best treatment results were those related to mobility, imbalance and fatigability. Absence of improvement was noted with regard to vision impairment following optic neuritis. Symptoms related to the sensory system and pyramidal tracts were resistant to treatment.

Despite the improvement in mobility, general symptoms of damage to pyramidal tracts were difficult to resolve. In the majority of patients there was an absence of remission in terms of pathological symptoms, such as Babiński and Rossolimo symptoms, reduction in spasticity and clonus as a result of treatment implementation. Similarly, via the Romberg test, a relatively small number of patients showed an improvement in controlling the sphincters of the urinary bladder, remission in intention tremor, while other cerebellum symptoms reacted more favourably to the treatment, such as ataxia, disdiachokinesia and imbalance.

In the analysis of the above material it needs to be said that our patients subjected to hyperbaric oxygenation represented a mild or average level of severity of their condition, whereas in the reviewed material the majority of patients were those with moderate or low disability (level 3 or 2 acc. to DSS). Following the hyperbaric oxygenation treatment implemented by the authors, observable improvement was noted in 13 patients, as expressed by mild or minimal level of disability. This is illustrated in table 3. 
Treatment results for $16 \mathrm{MS}$ cases subjected to hyperbaric oxygenation, evaluated according to the disability status scale prepared by Kurtzke.

\begin{tabular}{llll}
\hline Case no. & Results & Case no. & Results \\
\hline 1 & $2-1$ & 9 & $3-2$ \\
\hline 2 & $4-2$ & 10 & $3-1$ \\
\hline 3 & $3-2$ & 11 & $6-6$ \\
\hline 4 & $2-1$ & 12 & $3-2$ \\
\hline 5 & $3-2$ & 13 & $3-2$ \\
\hline 6 & $3-2$ & 14 & $2-1$ \\
\hline 7 & $6-6$ & 15 & $4-2$ \\
\hline 8 & $4-3$ & 16 & $2-1$ \\
\hline Note & & &
\end{tabular}

figure to the left indicates the patient's condition before the treatment.

figure to the right indicates the patient's condition after the treatment.

Currently, upon discharge from the Clinic of the Institute of Maritime and Tropical Medicine of Gdynia, our patients remain under the continuous specialist observation and supervision of the neurological department.

As mentioned before, in all cases three repeated immunological tests were carried out. It should be added that their interpretation allowed the adoption of standard values for immunoglobulins IgG of $639-1349 \mathrm{mg} / \mathrm{dl}$, IgM 50-250 mg/dl, IgA $70-312 \mathrm{mg} / \mathrm{dl}$, whereas for IgD this figure was up to $8 \mathrm{mg} / \mathrm{dl}$ while for complement activity, values determined via the $50 \%$ haemolysis method were found to be $20-50 \mathrm{u} / \mathrm{ml}$. The standard values for lymphocytes T and B adopted for tests were: for ARFC 16$33 \%$, TRFC $45-75 \%$, whereas for EAC $23-40 \%$.

With consideration of the above values, certain shifts in the examined immunological indicators were noted in MS patients' subjected to hyperbaric oxygenation, these being illustrated in table 4 for the determined immunoglobulins and complement and in table 5 for lymphocytes $\mathrm{T}$ and $\mathrm{B}$.

The behaviour of immunoglobulin values in MS patients subjected to hyperbaric oxygenation

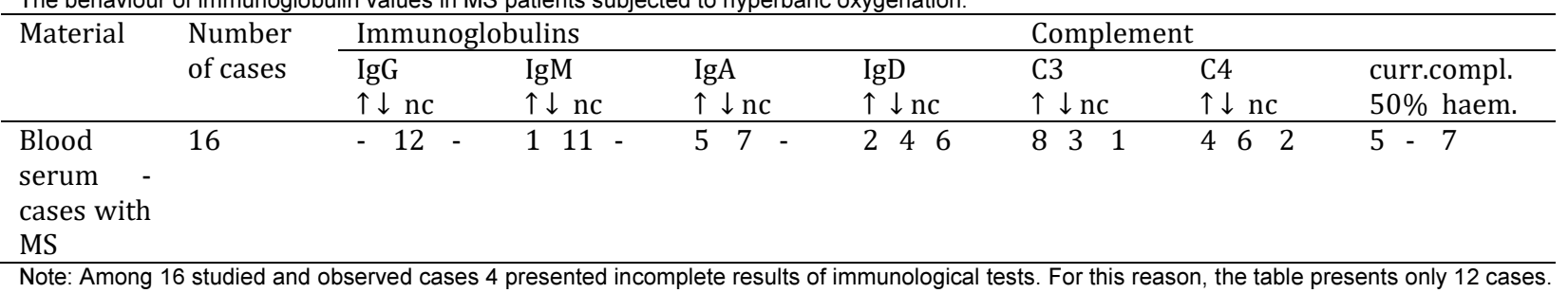

The behaviour of lymphocyte T and B values in MS patients treated with hyperbaric oxygenation

\begin{tabular}{|c|c|c|c|c|c|c|}
\hline \multirow[t]{3}{*}{ Material } & \multirow{3}{*}{$\begin{array}{l}\text { Number of } \\
\text { cases }\end{array}$} & \multicolumn{2}{|c|}{ Lymphocytes T } & \multicolumn{3}{|c|}{ Lymphocytes B } \\
\hline & & ARFC & TRFC & \multirow[t]{2}{*}{$\uparrow$} & \multirow{2}{*}{$\begin{array}{l}\text { EAC } \\
\downarrow\end{array}$} & \multirow[t]{2}{*}{ nc } \\
\hline & & $\uparrow \downarrow \mathrm{nc}$ & $\uparrow \downarrow \mathrm{nc}$ & & & \\
\hline $\begin{array}{l}\text { Peripheral } \\
\text { blood } \\
\text { lymphocytes }\end{array}$ & 16 & $\begin{array}{lll}6 & 5 & 1\end{array}$ & $66-$ & 6 & 4 & 2 \\
\hline
\end{tabular}

The above tables indicate that the majority of MS patients treated successfully with hyperbaric oxygenation showed an observable decrease in immunogloblins IgG and IgM, whereas immunoglobulins IgA and IgD did not present significant shifts. With regard to complement, an increase in C3 fraction was noted. The values of lympocytes T ("active" in ARFC tests and "total" in TRFC tests) and lymphocytes B (EEC tests), on the other hand, showed no characteristic shifts. In 2 MS cases (DS. and ChA) with negative treatment result, no changes characteristic of hyperbaric oxygenation were observed in relation to immunoglobulins and lymphocytes $\mathrm{T}$ and $\mathrm{B}$.

Due to the meagreness of the researched material we were unable to obtain full information on the behaviour of the values of immunological tests in MS patients treated with hyperbaric oxygenation, although certain immunosupressive activity of this factor in the said cases was noted (immunoglobulins IgG and IgM). It is therefore required to continue the research with consideration of an extended assortment of immunological tests.

In conclusion, it needs to be emphasised that the above work should be treated as preliminary with plans to continue the tests over a longer observation period and with 2 control groups (including one subject to hyperbaric air) and larger groups of subjects. 


\section{BIBLIOGRAPHY}

1. Barnes M., Bates D., Cartlidge N., Frenoh J., Shaw D. - Hyperbaries oxygen and multiple sclerosis: Short-term results of a placebo-controlled double blind trial. Lancet. 1985. Saturday 9 February 297-300.

2. Bauer H. - Problems of symptomatic therapy in Multiple Sclerosis. Neurol. 1978.28-2:8-20.

Bauer H. - Umstrittene MS-Therapie. Rühm Pharma. A 19.1983:400-405.

Borstein M., Miller A. - A Pilot Trial of Cop I in: Exacerbating-Remitting Multiple Sclerosis. New.Engl.J.Med.1987.317.7:408-4414

Brown J. - Problems in evaluating new treatment for Multiple Sclerosis. Neurol. 1980.30-2:8-11.

Caplan L., Nadelson T. - Multiple Sclerosis and Hysteria.AMA.1980.243:2418-2421.

Davis J. - Hyperbaric-Oxygen for patients with Multiple Sclerosis. New.Engl.J.Med.1984.1831:288-

Fisher B., Marks M., Reich T. - Hyperbaric-Oxygen treatment of Multiple Sclerosis. A randomized, placebo-controlled, doubleblind study.

Fronai C., Sereni G., Zannini D. - L'ossigenoterapia iperbarica nel trattemente della solerisi multipla. IV.Congr.Naz.SIMSI.Napoli 1980.

10. Gołowkin W.N., Zajcew W.S., Łotewin A.P. - Hiperbariczeskaja oxygenija kak immunostimulator pri Rassejanom Skleroze. Sow.Med.1985.2:22-26.

Gozzano M. - Sclerosi e placche. Trattato delie malattie nervosa. IV.Ed. Valdi. 1970. pp.642-659.

James P. - Evidence for subacute fat emnolism as the cause of Multiple Sclerosis. Lancet. 1982.6:380-386.

James P. - Oxygen for Multiple Sclerosis. Lanct. 1983.13:396-397.

14. Editorial Committee - Therapeutic claims in multiple sclerosis. Warsaw 1987. - trans. from the 2nd ed. of Therapeutic Claims in Multiple Scloerosis 1983.

15. Kurtzke J. - Further notes on disability evaluation in Multiple Sclerosis with scale modification. Neurol. 1965.15:654-661.

16. Kurtzke J. - A proposal for a uniform minimal disability in Multiple Sclerosis. Symp. On Multiple SclerosisService Functional Disability Ratings: Medical, Social and Economic Implications. Stockholm 1980.

17. Mertin J., McDonald W. - Hyperbaric-Oxygen for patients with Multiple Sclerosis with scale modification. Neurol, 1965.15:654-661.

18. Neubauer R. - Hyperbaric oxygen for multiple sclerosis. Lancet. 1985. April 6.: 810-

19. Neubauer R. - Treatment of Multiple Sclerosis with monoplace hyperbaric oxygenation. J.Fla.Med.Ass.1978.65:101

20. Pawelski S. - Laboratory diagnostics in haematology. PZWL. Warsaw. 1983. II. Ed. pp. 354-357 - Barbara Żupańska "Methods for lymphocyte determination in peripheral blood".

21. Perrins D. - Hyperbaric, Oxygen for patients with Multiple Sclerosis. Brit. Med. J. 1984.288:1229-1230.

22. Pugliese A., Missio C. - Ipotesi sull'eziologia della sclerosis multipla. Giorn. Batt. Virol. Immun. LXX. Luglio-Dicembre 1987:249-255.

23. Rose A., Kuzma J., Kurtzke J. et al. - Cooperative study in evaluation of therapy in Multiple Sclerosis.: ACTH with Placebo in acute exacerbations. Preliminary report. Neurol. 1968. 18/ suppl./:1-10

24. Wiles C., Clarke C., Irvin H., Edgar E., Swan A. - Hyperbaric oxygen in multiple sclerosis: A double blind trial. Brit. Med. J. 1986. 292.8 Febr.:367 - 371.

25. Zannini D., Formai C., Bogetti B., Sereni G. - Osservazioni su 40 casi di sclerosi multipla trattati con ossigenoterapia iperbarica. Med. Subq. Ed Iperb. 1982.2.1:1-7.

26. Zannini D., Ulewicz K. - Ossigenoterapia iperbarica ed immunopatologia. VII. Congr. Di Med. Subaq. Ed Iperb. Palermo 7-9 nov. 1986.

+). In Poland approximately 48000 people are treated for MS.

Disability status due to SM

Acc. to Kurtzke's Disability Status Scale

0 - normal neurological exam.

1 - minimal signs, e.g. Babiński's symptom

2 - minimal disability, e.g. slight paresis

3.- moderate disability, ambulatory patient, e.g. monoparesis, moderate ataxia.

4 - relatively severe impairments, still ambulatory patient.

5 - severe disability, patient does not walk more than a few steps.

6 - patient walks only on crutches

7 - patient wheels self in wheelchair.

8 - patient restricted to bed, has effective use of arms.

9 - helpless bed patient.

10 - death due to MS. 